\title{
Variation of Carbon Monoxide Concentrations as Related to Sampling Interval, Traffic and Meteorological Factors
}

\author{
R. A. MCCormick ${ }^{1}$ and C. Xintaras ${ }^{2}$ \\ Division of Air Pollution, Robert A. Taft Sanitary Engineering Center, Cincinnati, Ohio
}

(Manuscript received 17 November 1961, in revised form 22 January 1962)

\begin{abstract}
Diurnal variations of carbon monoxide concentrations and traffic density, exemplified in the literature as common for urban areas, were observed at "curb-side" studies in Nashville, Tenn., and Cincinnati, Ohio. A new technique is suggested for evaluating the effect of changes in traffic density on CO concentrations which may be useful for urban planning purposes and for appreciating the role wind speed can play to modify these assessments.

Peak to mean ratios of $\mathrm{CO}$ concentrations at Cincinnati were in the same range, 2:1-3:1, as those reported in single-source experiments in open terrain in which the source and receptor were located at the same height. In both cities, the decrease of the average ratios, $\chi_{7} / \chi_{60}$, (maximum short-period CO concentrations within the hour to the mean value over the hour) with increasing $\tau$, proceeds at a somewhat slower rate for $\tau>3$ min than in single source cases. Multiple and indefinite sources of $\mathrm{CO}$ in the immediate area of the urban sampling sites undoubtedly account for this by providing an atmosphere which is never entirely free of $\mathrm{CO}$ contamination.
\end{abstract}

\section{Introduction}

Carbon monoxide (CO) is an excellent tracer substance for the study of the variability in concentration of gaseous effluents from important pollutant sources in urban areas. It is found in significant concentrations, from less than 5 to greater than $100 \mathrm{ppm}$ (parts per million, by volume), which can be measured with an accuracy of better than $1 \mathrm{ppm}$; there are no known atmospheric or terrestrial sinks of the gas (Altshuller, 1958), and its primary source is vehicle exhaust and therefore near ground level.

This paper is a report on unbroken series of continuous observations of $\mathrm{CO}$ concentrations at "curb-side" in Nashville, Tenn., 26 April to 5 May 1959, and in Cincinnati, Ohio, 10 to 26 May 1960. The diurnal variation of mean hourly values and the ratios of maximum short-period concentrations to the hourly values $\left(\chi_{\tau} / \chi_{60}\right.$ where $\left.\tau<60\right)$ have been studied with respect to the variation in traffic density and meteorological factors.

The sensing instrument used at both locations was a continuous recording, MSA Lira Luft-type, nondispersive infrared analyzer. The sum of the calibration and recording errors is estimated to be no more than $\pm 0.8 \mathrm{ppm}$ at a $\mathrm{CO}$ concentration of $10 \mathrm{ppm}$. The chart speed of the recorder was set at 4 inches per hour so that 3-min averages could be read directly from the

\footnotetext{
1 Meteorology Section, Weather Bureau Research Station, Laboratory of Engineering and Physical Sciences.

${ }^{2}$ Aerometric Section, Field Studies Branch.
}

charts. In Nashville the analyzer was operated at a pressure of $40 \mathrm{psi}$ (pounds per square inch) so that the response to a change in concentration was such that the indicated reading of the recorder reached 85 per cent of the true value within $5 \mathrm{~min}$. Because of the relatively slow response, concentrations over 6-min intervals represent the shortest periods studied. In Cincinnati, however, the speed of response was increased by operating at atmospheric pressure and 85 per cent of the true concentration change was recorded within $20 \mathrm{sec}$.

\section{Nashville data collection}

The $\mathrm{CO}$ concentration data for Nashville were obtained at a location adjacent to the northeast corner of 9 th and McGavock Streets, station 60 of the Nashville Study (Zeidberg et al., 1961). The intersection, Fig. 1 , is 2 or 3 blocks south of the center of the downtown area. The analyzer was mounted in a van parked near the corner of a small parking lot. The intake orifice was situated about $2 \mathrm{ft}$ above the roof of the van, or about $12 \mathrm{ft}$ above street level. Hourly meteorological data were not available at the site, but wind speed and direction were available at station $52,2 \mathrm{mi}$ SSW of station 60 at an altitude about $230 \mathrm{ft}$ higher than station 60. Standard meteorological data were available from the Weather Bureau Airport Station, a little more than $6 \mathrm{mi}$ to the southeast. The distance and elevation of station 52 from the CO sampling site were not ideal for depicting the details of air flow at station 60. Station 52 is probably more representative of the 


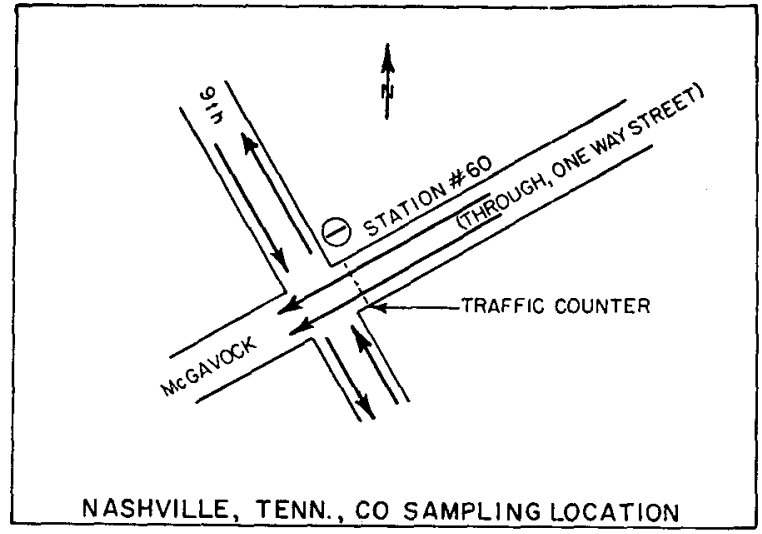

Fig. 1. Nashville, Tenn,, CO sampling location.

less disturbed general flow over the city, and somewhat lower wind speeds and greater turbulence would be expected at the $\mathrm{CO}$ receptor than those indicated by the station 52 wind sensors.

\section{Cincinnati data collection}

In Cincinnati both the $\mathrm{CO}$ and wind data were obtained at a site adjacent to Columbia Parkway, about 6 mi east of the downtown center (Fig. 2). The intake probe to the analyzer was located $5 \mathrm{ft}$ above ground level. Continuous wind speed and direction were recorded by a sensitive instrument (starting speed $<1 \mathrm{mph}$ ), mounted on a mast $18 \mathrm{ft}$ above ground level at the site. Standard meteorological data were available from the Lunken Airport Station, located about $1 \frac{1}{2} \mathrm{mi}$ south of the sampling area.

\section{Discussion of hourly data}

The pattern of diurnal variation in $\mathrm{CO}$ and traffic density, exemplified in the literature as common for urban areas, was observed at the Nashville and Cincinnati sites, Figs. 3 and 4 . The morning and evening

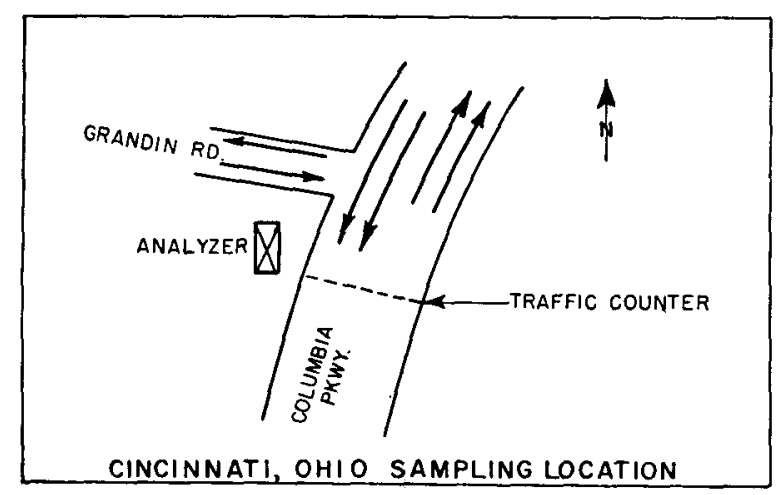

FIG. 2. Cincinnati, Ohio, sampling location. weekday maxima of both variables are well marked and the nearly parallel departures from that pattern over the weekend point rather convincingly to the dominant role of automobile exhaust as the source of $\mathrm{CO}$ at these sites. The $\mathrm{CO}$ concentrations at Nashville were some 2-4 ppm higher than in Cincinnati even though the traffic density was greater in Cincinnati. This anomaly is attributed to the difference in the representativeness of the traffic counts at the two sampling stations. The Nashville site was situated within a pool of sources including traffic on adjacent streets in the downtown area, but only vehicles on McGavock Street were counted. On the other hand, the Cincinnati site was relatively isolated from other than immediate sources, since the Parkway is the only significant avenue of traffic in the near vicinity. It appears that the respective traffic counts at the two sites may not reflect precisely the relative number of sources contributing to the "base" levels of CO. The primary difference in the traffic patterns at the two sites is that, of the possible modes, i.e., acceleration, cruise, deceleration and idle, only in the vicinity of the Nashville station would vehicles in the idle cycle be very frequent. This is because traffic on 9th Street had to stop at McGavock and parking was permitted on 9th adjacent to the station. Back-up of traffic from a signal light about one block north of the station on Columbia Parkway in Cincinnati rarely extended to the station even in the evening rush hours. The effect, if any, of the traffic in the idle cycle in Nashville in raising the mean $\mathrm{CO}$ levels higher than at Cincinnati is, however, a matter of conjecture.

No effects of wind direction or distance from the traffic sources were obvious. This might have been expected at Cincinnati (Fig. 4), since the evening traffic is predominantly outbound and therefore was farther away from the sampling intake. The maximum $\mathrm{CO}$ concentration in the evening is as great, however, as that in the morning in proportion to the traffic. Future studies of traffic patterns undoubtedly will resolve this anomaly.

Although qualitative agreement was good between the traffic count and CO shown in Figs. 3 and 4, which depict average conditions, the statistical correlation between these quantities was not impressive, since it was on the order of only 0.60 at both cites. This is in contrast to a recent study, (Brief, et al., 1960), which reported an unspecified but "highly correlated relation." From our study it must be assumed that simple hourly traffic counts do not represent adequately source strength variations and/or that the meteorological influences on observed $\mathrm{CO}$ concentrations are important.

Meteorological influences on observed concentrations arise from effects of wind speed, turbulence and stability in the atmospheric layers near the ground. No direct measures of stability were made at either site, 


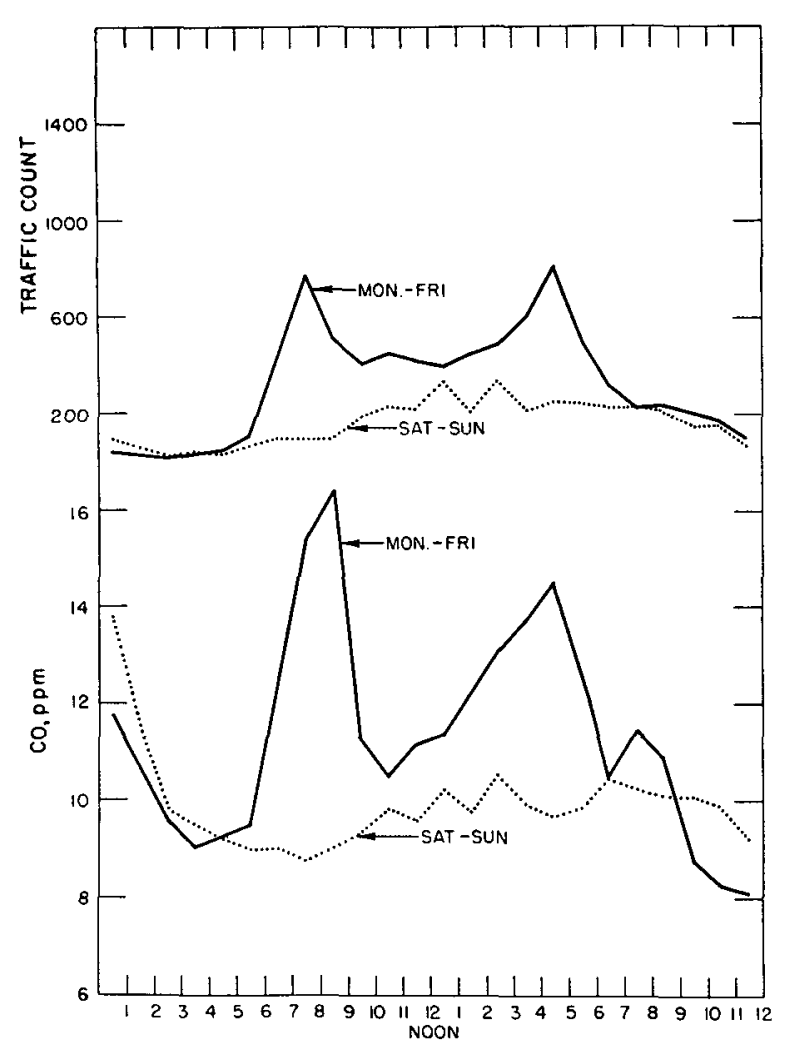

FIG. 3. Hourly traffic count and CO, Nashville, Tenn.

but radiosonde observations were made twice each day at the Nashville Airport. Although this information was examined closely, it was not found useful in the interpretation of the data collected in this study. A purely empirical factor therefore was adopted as a stability index, based on wind speed, sky cover, season and time of day. This empirical factor, which Turner (1961) has found useful for depicting the gross stability condition over Nashville at any time, was used at both cities.

Because of the mobility of the sources and the varying source-receptor geometry, the vagaries in the transport of $\mathrm{CO}$ from source to receptor by air movements are difficult to assess, even qualitatively, in terms of wind speed and stability. In addition to any "natural" wind that may exist, passing cars create "artificial" gusts and flurries that unquestionably play an important role in the local dispersion of exhausted gases and particulates. During periods of very light "natural" winds or calm, this mechanical mixing by passing cars conceivably could cause the transport of larger quantities of $\mathrm{CO}$ to the sampling receptor than would have been possible by molecular diffusion alone, particularly when as in our case, the receptors were some distance away from and at a greater elevation than the sources. During higher winds it is more likely that the effect of the flurries was additive, increasing

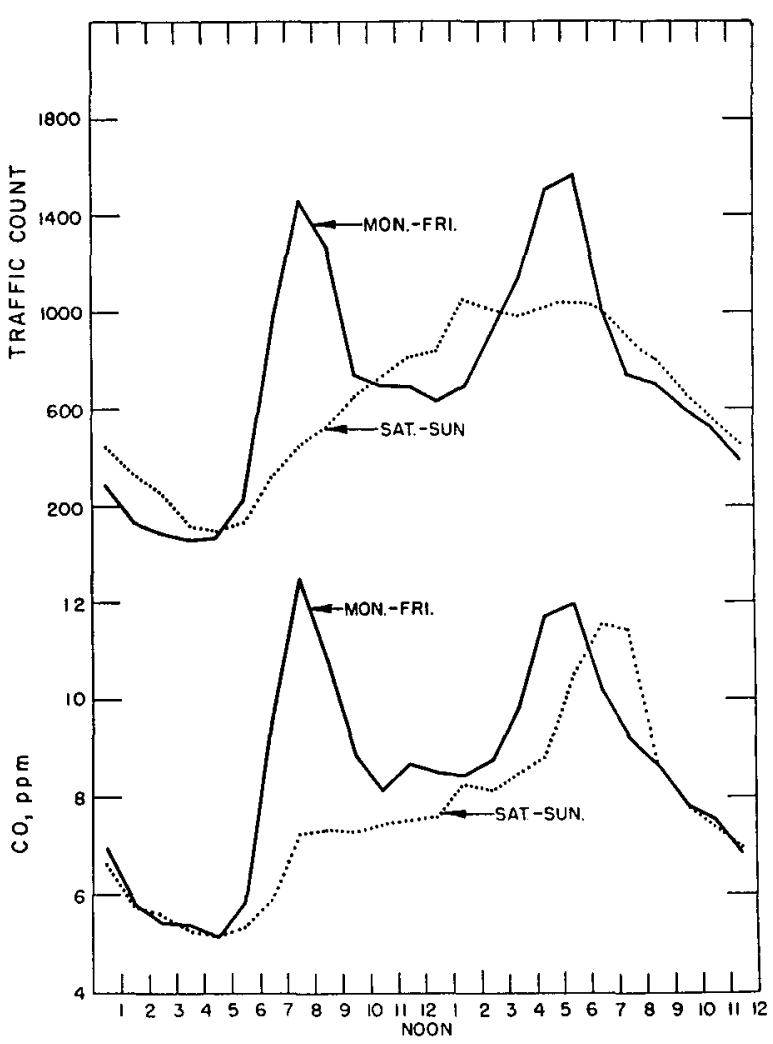

FIG. 4. Hourly traffic count and CO, Cincinnati, Ohio.

the dispersion or dilution of the $\mathrm{CO}$, although situations could be envisioned in which this would not be the case. Fig. 5 is illustrative of the relationships that might be expected between wind speed and $\mathrm{CO}$ for source and receptor at the same and at different elevations, but with other factors of source-receptor geometry and stability conditions equal.

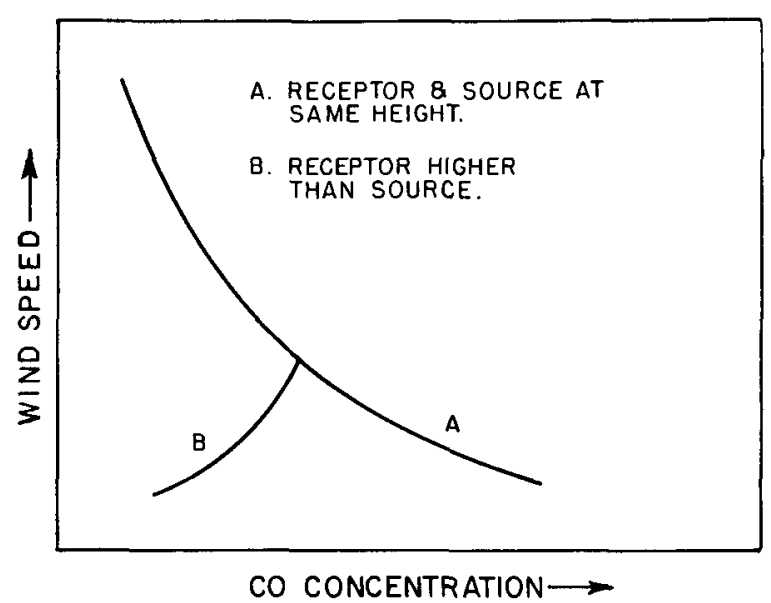

FIG. 5. Possible relationship between $\mathrm{CO}$ and wind speed. 
It is commonly accepted that increased atmospheric stability results in increased concentrations of pollutants, as a result of the damping influence of stable layers on turbulent, dispersive air motions (eddies) within the layer. Again, however, the usual concept may not hold when the receptor is at a different elevation than the source. If the difference is appreciable and mechanical mixing is absent, increased stability could decrease concentrations at the receptor. Our experiments were not definitive in resolving the effects of stability on the $\mathrm{CO}$ concentrations. Mechanical mixing by the passing traffic was occurring at all times to some degree. At Nashville, however, where the CO receptor was the higher, on clear, "stable" nights concentrations were lower in relation to the traffic count than on cloudy, less-stable nights. The question of cause and effect remains unresolved, nevertheless, since on cloudy nights wind speeds were greater.

In Nashville, remote wind measurements were used, whereas in Cincinnati wind sensors were located near the $\mathrm{CO}$ analyzer. In both cites very low statistical correlations were found between $\mathrm{CO}$ and hourly wind speed, wind direction, and stability, respectively. Some support was found, however, for the hypothesized relative consequences of low and high winds, in that the correlation was negative at Nashville (mean wind speed about $7 \mathrm{mph}$ during the study) but positive at Cincinnati (mean wind speed about $3 \mathrm{mph}$ ). At Cincinnati the wind sensors were responsive to the vehicleinduced flurries, although not to the extent that the passage of each car showed on the record. Experience suggests that in future studies of this kind the combined effects of the natural wind and the flurries should be measured as near the sampling orifice as possible without sensibly affecting the air flow. Hot wire anemometry might be the best technique. A direct measure of the low-level stability in the immediately vicinity of the site also would be desirable. Preliminary experiments on the behavior of visible smokes emitted from the exhaust pipes of (stationary) cars in calm conditions suggest that net radiation measurements may be useful for this purpose.

Although the poor correlation between $\mathrm{CO}$ and wind speed, in the gross sense, cannot be disputed, some important $\mathrm{CO}$ anomalies, or departures from the diurnal pattern, can be interpreted reasonably in terms of the wind speed behavior. An extreme example is shown in Fig. 6, which presents the hourly progression of wind speed, traffic count, and CO in Nashville from 3:00 pm, 28 April to 4:00 am, 29 April. The increase in $\mathrm{CO}$ despite the decrease in traffic is attributed to the lower wind speed and the diminished mixing or dispersion of $\mathrm{CO}$ at street level; the role of stability during this period is indeterminate.

The trends of $\mathrm{CO}$ concentration and traffic density, Fig. 6 , in relation to wind speed were investigated for
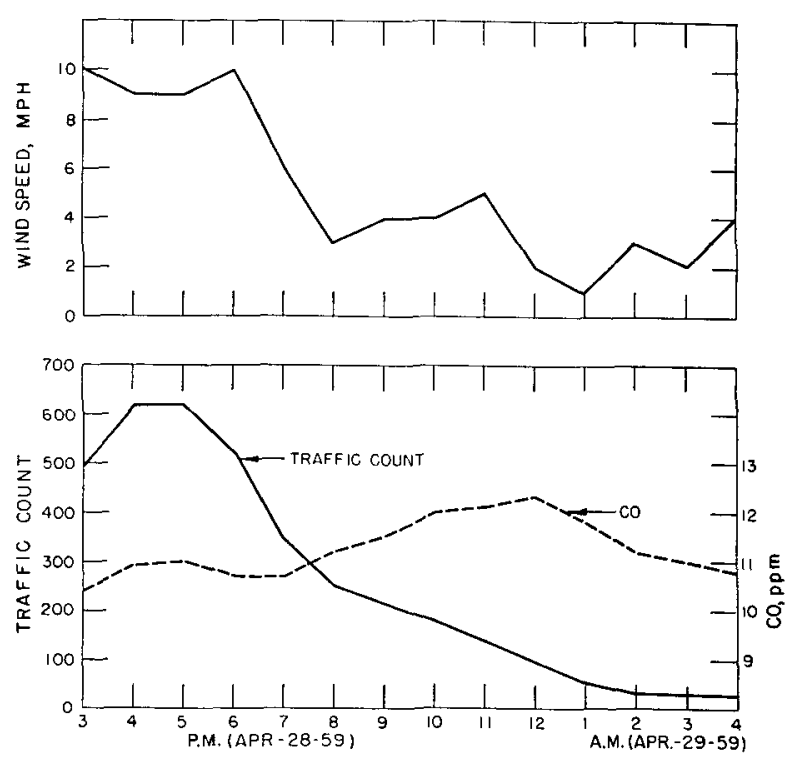

FIG. 6. Hourly values of CO-traffic count-wind speed, Nashville, Tenn.

all hours during which the change in traffic count from the previous hour was appreciable $(\geq 100)$. Figs. 7 and 8 show the best relationships found; these were applicable in about 75 per cent of the cases. For example, at Nashville if the traffic count for a particular hour was 200 greater than for the previous hour $\left(\Delta T_{c}=200\right)$ and the wind speed was average (about $7 \mathrm{mph}$ ), then the mean $\mathrm{CO}$ concentration for that hour could be expected to be about $0.9 \mathrm{ppm}$ higher $(\Delta C=0.9)$ than for the previous hour (Fig. 7A). The increase in concentration would be more than $0.9 \mathrm{ppm}$ if the wind speed was less than $7 \mathrm{mph}$, and less than $0.9 \mathrm{ppm}$ if the wind exceeded $7 \mathrm{mph}$. Fig. $7 \mathrm{~b}$ shows the effects of decrease in traffic density in decreasing the CO levels, along with the influence of wind speed. Stability considerations did not help resolve the interdependency of these factors.

Figs. 7 and 8 should be considered only as indicators of trends derived from very limited periods of records in a specific season. It should be pointed out that:

(1) The scatter of the original data points (53 for Nashville, 165 for Cincinnati) in the figures was quite large and in a significant number of cases ( $\sim 25$ per cent) the wind speed class was opposite to that indicated by the figures for a given $\Delta T_{c}$ and $\triangle \mathrm{CO}$.

(2) The $\Delta \mathrm{CO}$ dependence on the magnitude of the wind speed is poorly resolved.

(3) The respective wind speed classifications are unlikely to have general significance or to be applicable to other wind-measuring sites in the two cities. 

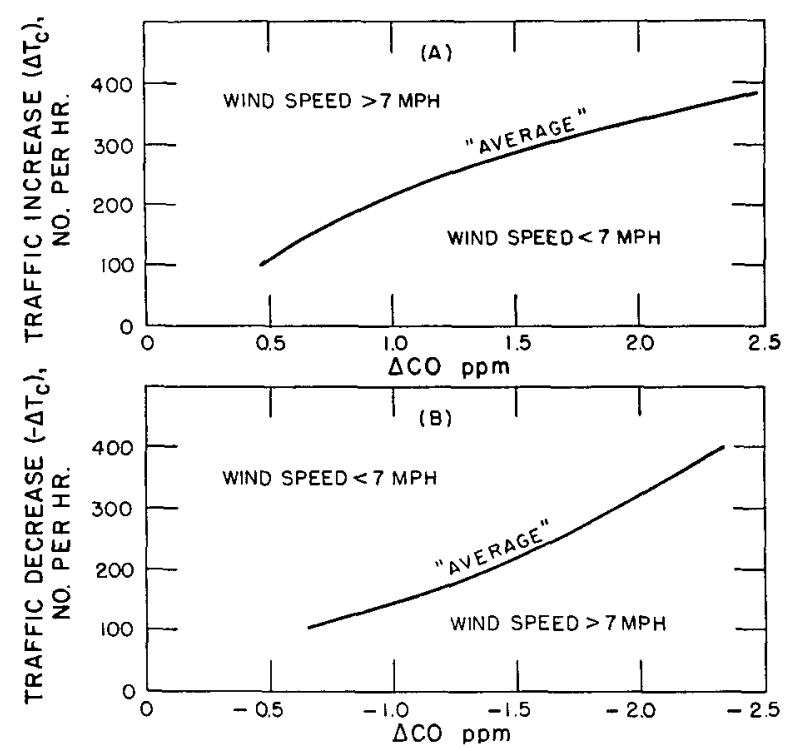

FIG. 7. Change in $\mathrm{CO}$ as related to wind speed and change in traffic density, Nashville, Tenn.

The real utility of this study is in its suggestion of a technique for evaluating the effect of a change in traffic density on $\mathrm{CO}$ concentrations. Such a technique might be useful in urban planning. With more extensive data from permanent wind measurement sites, more stable and definitive charts probably could be derived for any specific location.

\section{Discussion of ratio of maximum to mean con- centrations}

The ratios of the mean maximum short-period $\mathrm{CO}$ concentrations within the hour to the mean for the hour, $\chi_{\tau} / \chi_{60}$, for $\tau=6,15$, and $30 \mathrm{~min}$ are shown for Nashville by hour of the day in Fig. 9. Similarly, the ratios of $\chi_{\tau} / \chi_{60}$ for $\tau=3,6,15$, and $30 \mathrm{~min}$ for Cincinnati are given in Fig. 10, along with peak to mean ratios, $\chi_{p} / \chi_{60}$. The scale of the ordinate in Fig. 9 is expanded relative to that in Fig. 10. Lines are drawn between the points merely to aid in the discrimination among $\tau$ classes.

Comparison of these data with the findings presented by Gifford (1960) shows that the peak to mean ratios at Cincinnati are in the same range, $2: 1-3: 1$, as those reported by Gifford from single-source experiments in open terrain in which the source and receptor were located at the same height. In both cities, however, the decrease of $\chi_{\tau} / \chi_{60}$ with increases in $\tau$ proceeds at a somewhat slower rate for $\tau>3 \mathrm{~min}$ than it did in the single-source cases. The multiplicity and omnipresence of sources in the two cities undoubtedly accounts for this, since an ambient atmosphere is provided that is never entirely free of $\mathrm{CO}$ contamination. Thus, air
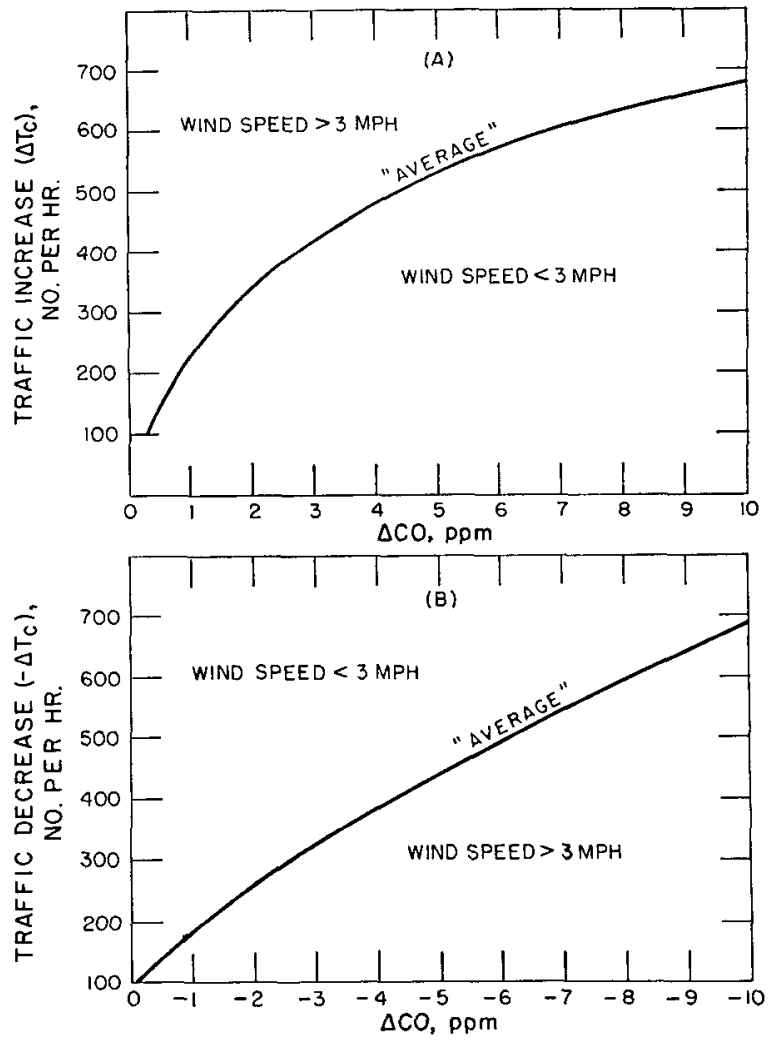

FIG. 8. Change in $\mathrm{CO}$ as related to wind speed and change in traffic density, Cincinnati, Ohio.

without $\mathrm{CO}$ is never available with which newly created $\mathrm{CO}$ can mix, and therefore mean $\mathrm{CO}$ concentrations always are relatively high with respect to the $\chi_{r}$.

For comparable values of $\tau$, the ratios are much smaller for Nashville than for Cincinnati. Several factors probably contribute to this, such as the over-all higher hourly means in Nashville, and the greater mechanical mixing by faster-moving traffic past the Cincinnati site. The effect of distance is probably not negligible. The receptor of the $\mathrm{CO}$ analyzer was $12 \mathrm{ft}$ above the ground in Nashville and $5 \mathrm{ft}$ above the ground in Cincinnati. Because of stability complications, the damping of $\mathrm{CO}$ variations with height could not be determined from our data; this determination would require simultaneous measurements at several heights.

Although the variations of $\chi_{\tau} / \chi_{60}$ with $\tau$ are small, particularly at Nashville, they are statistically significant in that the probability that the observed differences arose from pure chance is less than 1 in 100 . The parallelism of the arrays and the simultaneity of nearly all peaks and valleys provides some insight into the phenomena responsible for the $\mathrm{CO}$ fluctuations. The scales of these fluctuations are evidently large as indicated by $\chi_{\tau} / \chi_{60}$ peaks for short periods, which invariably are associated with $\chi_{30} / \chi_{60}$ peaks, not with isolated short-period surges. The major peaks during 


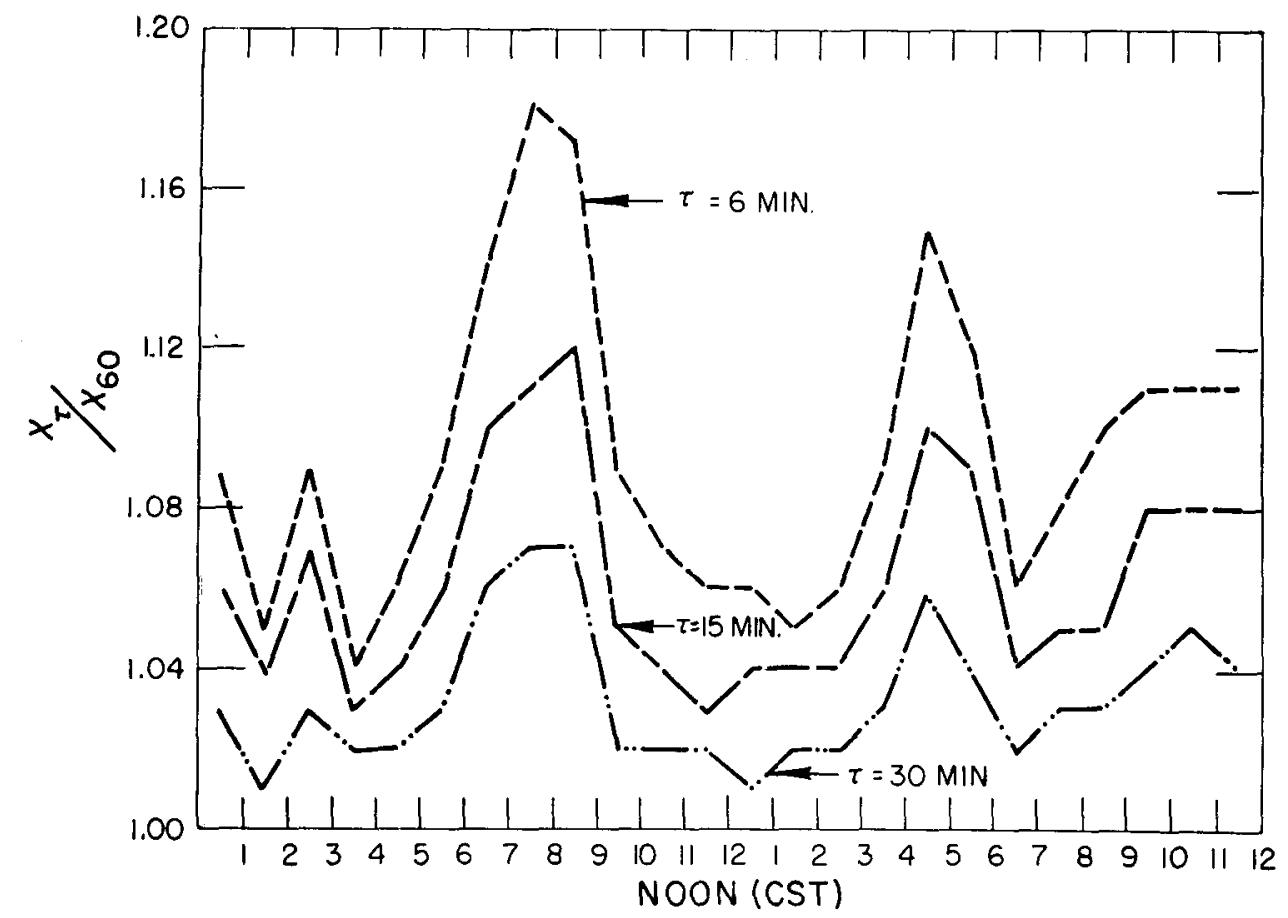

FIG. 9. Ratio of maximum to $1-\mathrm{hr}$ mean $\mathrm{CO}$ concentration as function of averaging time and time of day, Nashville, Tenn., 26 April-5 May 1959.

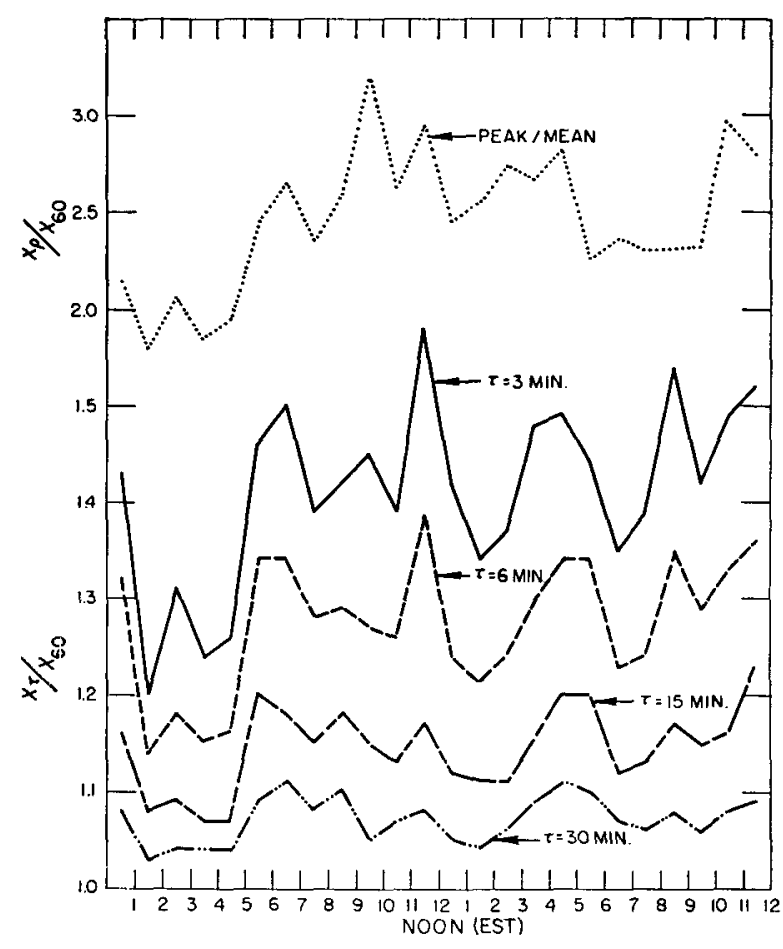

Ftc. 10. Ratio of maximum to 1-hr mean CO concentration as function of averaging time and time of day, Cincinnati, Ohio, 10-26 May 1960. the middle of the day in Cincinnati indicate that the peaks may not be merely a result of the diurnal $\mathrm{CO}$ maxima brought on by high traffic density, as the Nashville data seem to suggest. Although the contrast between Nashville and Cincinnati is striking, it is somewhat exaggerated by the difference in the ordinate scales of the figures. A logical and physically reasonable interpretation, in terms of source and meteorological factors, of the $\chi_{\tau} / \chi_{60}$ variation through the day at Nashville might be made. The apparent randomness of these variations at Cincinnati, however, except possibly during the very early morning hours, would contradict the generality or perhaps even the truth of such an interpretation. As a result we see no alternative but to leave the question of the respective causes for the observed dirunal variations in $\chi_{p} / \chi_{60}$ unanswered pending further and more detailed study.

\section{Conclusions}

This investigation has shown that in urban areas some order can be found in $\mathrm{CO}$ fluctuation with time but that a complete interpretation of such "curb-side" data in terms of source and meteorological factors is very complex. The hourly variation of $\mathrm{CO}$ concentration with traffic density has confirmed a moderate degree of correlation between these two factors; however, this limited correlation at the same time empha- 
sizes the importance of local conditions of transport and dispersion on this variation. Marked positive anomalies of the normal $\mathrm{CO}$ trends can be associated with wind speed decay, and therefore a technique has been suggested for evaluating the effects of traffic changes on $\mathrm{CO}$ levels with wind speed incorporated as a contributory element.

The results of single-source field experiments validate to some extent the interpretation of data collected in Nashville and Cincinnati. Reasonable first-approximation estimates of the higher short-period concentrations during 1-hr sampling periods is now possible. Further information on the diurnal variation of the ratios will be required, however, before the general effect of time of day on the estimates can be determined.

Acknowledgments. The authors would like to express their gratitude to many of their colleagues at the
Robert A. Taft Sanitary Engineering Center, particularly W. Stalker, C. E. Zimmer, D. B. Turner, C. R. Claydon and W. E. Umfleet for their assistance in the collection and reduction of the $\mathrm{CO}$ and meteorological data.

\section{REFERENCES}

Altshuller, A. P., 1958: Natural sources of gaseous pollutants in the atmosphere. Tellus, 10, 479-492.

Brief, R. S., A. R. Jones and J. D. Yoder, 1960: Lead, carbon monoxide, and traffic. $J$. air poll. cont. Assn., 10, 384.

Gifford, F., 1960: Concentration ratios according to a fluctuating plume dispersion model. Int. J. Air Poll., 3, 253.

Turner, D, B,, 1961: Relationships between 24-hour mean air quality measurements and meteoroligical factors in Nashville, Tennessee. J. air poll. cont. Assn., 11, 483.

Zeidberg, L. D., J. J. Schueneman, P. A. Humphrey and R. A. Prindle, 1961: Air pollution and health: General description of a study in Nashville, Tenn. $J$. air poll. cont. Assn., 11, 289. 